\title{
PROPOSAL FOR THE
}

\section{EXPERIMENTAL DEMONSTRATION OF THE COHERENT RADIATION*}

\author{
A.G. Ruggiero \\ Brookhaven National Laboratory \\ Upton. NY 11973. USA
}

\section{INTRODUCTION}

It is of great importance to provide an experimental demonstration of the coherence of the radiation of electromagnetic waves from a short bunch of electrons performing oscillations in a direction transverse to the main direction of motion.

It is known that electrons circulating in a storage ring lose energy to synchrotron radiation." Another method to stimulate radiation is to let an electron bunch travel through a wiggler or an ondulator device." In either case the spectrum usually peaks in correspondence of wavelengths considerably smaller the length of the electron bunch: in this situation the power radiated is then linearly proportional to the number $N^{*}$ of electrons in the bunch. as it is customarily observed. ${ }^{3}$ Nevertheless. it maty be possible conceiving a situation where the bunch length is consiclembly smaller or at keast comparable to the wavelength of the peak of the radiation spectrum. If this is the case. it is then speculated that the power racliated is proportional to the square. $V^{2}$ of the number of particles in the bunch. This effect. which we can call a coherent effect is of course very important since it would help to enhance the amount of the power radiated with a lower electron intensity.

Lnfortunately the coherent effect is difficult to observe since it is not casy to create bean and trajectory parameteds wheh yield a bunch of length smaller than the radiation wavelength." ${ }^{0}$ Ho thes propose here an experinent which has the two goals: (i) to generate an experimental situation where electrons in a bunch of le agth radiate electromagnetic power at a variable wavelength $\lambda$. and (ii) to ooserve with measurements the cotal anount of radiation versus $\lambda$ and the beam intensity $X$. This cxperinent can be executed at the Accelerator Test. Facility either at Brookhawen or at Argonne National Laboratory".

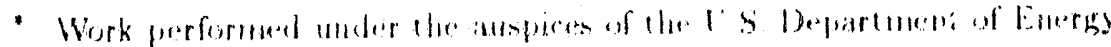

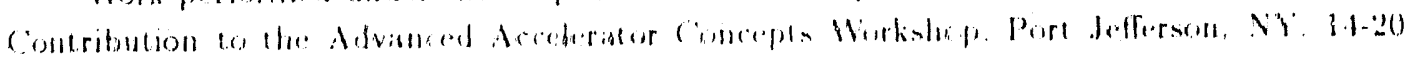

luss: 11,192

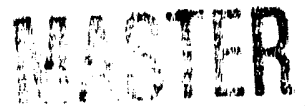

of 


\section{EXPERIMENTAL APPARATUS}

The experimental apparatus is simple and shown schematically in Fig. 1. It takes at the start a short bunch of electrons at the relatively low energy of $4 \mathrm{MeV}$. It is important that the electron bunch is as short as possible. Beam intensity is not very crucial; actually a lower intensity is preferable to control easily both the bunch length and the transverse emittance. The experiment needs to make only relative measurements of the electromagnetic power being radiated and the beam intensity is to be large enough to allow easy detection of the radiation. We assume that the bunch length is 6 psec and the normalized transverse emittance is $4 \times 10^{-6} \pi \cdot \mathrm{mm} \cdot \mathrm{mrad}$. A beam intensity with a peak value of $0.1 \mathrm{n}$ Coulomb may be required.

At the exit of the electron gun there is a conventional wiggler magnet with a field variable up to $1 \mathrm{kG}$ and a period of $40 \mathrm{~cm}$. The wiggler is $4 \mathrm{~m}$ long and thus is made of ten periods. The devices can be made of conventional magnets with quadrupoles included for focusing. A magnet gap of few $\mathrm{cm}$ is adequate for letting the beam through. Previous experiments ${ }^{6,7}$ employed conventional bending magnets for the production of synchrotron radiation. The use of a wiggler, as proposed here. is more advantageous since it provides a better defined and controlled radiation wavelength.

Leaving the wiggler, the electron bunch enters a bending magnet which deflects the beam away toward a collector for energy recovery, or toward a durnp underground. At the same time the radiation traveling in a straight line will leave the bending magnet and enter a radiation detector. The bending magnet has a field of $1.0 \mathrm{kG}$ and a length of $0.2 \mathrm{~m}$ for a bending angle of $20^{\circ}$. It may be useful that a data gathering, is attached to the radiation detector for the collection of the experimental results and subsequent data analysis. At the same time it will be important to gather information on the bunch Jength. transverse dimensions and intensity. The clectron beam energy and the wiggler field are also to be recorded.

\section{THE ELECTROMAGNETIC RADIATION}

The elertrons going through the wiggler magnet perform transverse oscillations with a period given by the period of the wiggler $2 h^{\prime}$ and an amplitude which depereds on the wiggler field $B_{1}$ and the magnedic rigidity $(B$,$) of the$ particles arcording to the following formula

$$
u=\frac{(B \rho)}{B_{u n}}\left[1-\sqrt{1-\left(c_{u} B_{w} / 2 B \rho\right)^{2}}\right] .
$$

With a field of 250 Cinuss one derives an anplitude of oscillations of 8.4 mm.

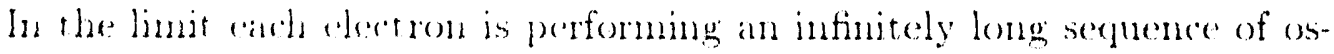

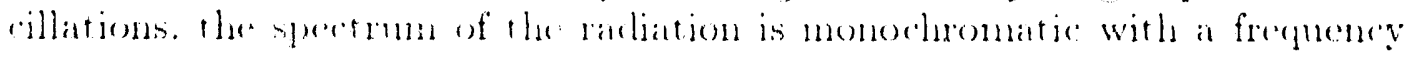
corresponding to the warkelength

$$
\lambda_{1}=i \ldots / 7, i^{\prime}
$$


which, with the values of the parameters taken above, gives $2.6 \mathrm{~mm}$. This is about the assumed bunch length $\rho_{e}=2 \mathrm{~mm}$. The only way to increase the radiation wavelength is by increasing also the wiggler period or lowering the beam energy. But it is clear that there are conflicting requirements and that it is not indeed easy to fulfill the coherence regime obtained with $\ell_{e} \gg \lambda_{r}$.

Since the electrons are performing in the experimental set up only ten oscillations, the radiation will have a wider spectrum with a bandwidth around the critical frequency of about $10 \%$. Moreover the radiation has spatial distribution with an angular aperture of about $1 / 7 \sim 100$ mrad.

The total energy radiated for the case the bunch is made of a single electron is given by

$$
W_{0}=(56.3 \mathrm{keV}) \frac{E^{4}}{(B \rho)} n B_{u} \arcsin \left\lfloor\frac{l_{w} B_{w}}{2(B \rho)}\right\rfloor
$$

where $(B \rho)$ is the particle rigidity in Gauss meter, $E$ the kinetic energy in $\mathrm{GeV}, n$ the number of periods in the wiggler, $2 \ell_{w}$ the period length in meter and $B_{w}$ the wiggler field in Gauss.

In the approximation of a long bunch with $N$ electrons the total energy radiated by the bunch is

$$
W_{L}=N W_{U}
$$

whereas in the limit of a very short bunch, because of the coherence effect the total power radiated is

$$
W_{s}=N^{2} W_{0}
$$

As an example, let us take $B_{u}=250$ Gauss and $\mathrm{V}=1 \times 10^{9}$ electrons, then

$$
\begin{aligned}
& H_{0}=40 \mathrm{mV} \\
& H_{1}=40 \mathrm{keV} \\
& H_{1}=40 \mathrm{~T} 0 \mathrm{~V}
\end{aligned}
$$

At the reperition rate of $t() \mathrm{MH}$ the a wower for the short bunch ease is $260 \mathrm{MV}$. asily detectable. In the case of long bunches the power level is nine orders of magnitude lower and thus more difficult to measure.

\section{MEASUREMENTS}

It is thus ronceived that on propesal in a "yes" or "uo" experinent. If any" radiation will be observed in signitiont anomat it will be caused by cobterence effects: if no raliation is masmed the same effects can be quesponed.

To preform a complete set of masistentents to demonstrate further the

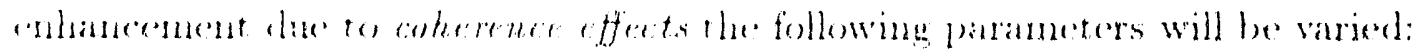

a) The wiggler field $B_{u}$. This will viry the amplitule of the ossellation

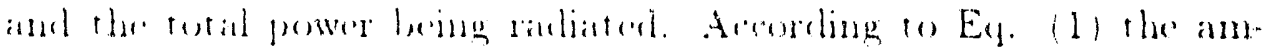

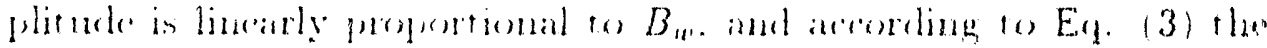

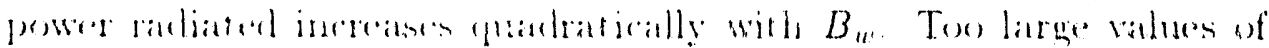

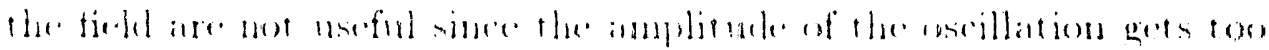


large and it will make the source spot size of the radiation also too large to be detected.

b) The number $N$ of electrons. Depending on whether the coherence effects are present, the power radiated will have either one of the two dependencies shown by Eqs. ( 4 and 5 ). Moreover, in the case the bunch length is just about equal to the radiation wavelength, one can expect a mixture of $N$ and $N^{2}$ dependencies. A plot of measurements of power versus $N$ is then very useful.

c) The beam energy. For a fixed length of the wiggler period, the only way to vary the wavelength of the radiation is to change the beam energy according to $\mathrm{E}_{\mathrm{q}}$. (2). By increasing the beam energy, the power radiated of course increases, but the wavelength will correspondingly decrease and the dependence with the number $N$ of particles should become more linear.

In summary, it is important to have the possibility of varying and measuring the wiggler field $B_{u}$. the beam intensity.$V$ and the bean energy $\gamma$. It is assumed that the control and reading of the last two parameter's is provided by the Accelerator Test Facility itself: the control and measurements of the wiggler tield will be included in the design of the wiggler itself.

\section{TRANSVERSE FOCUSING}

An important requirement for this experiment is to keep the transverse bearn bunch size to a dimension smaller or comparable to the radiation wavelength. At the energy of $4 \mathrm{MeV}$ the betatron enittance is $0.4 \pi \mathrm{mm} \cdot \mathrm{mrad}$. and one will need a strong focusing system to keep the bunch size to around a millimeter. For this purpose. quadrupoles with altemating gradients ( $Q F$ and QD) in a FODO cell arrangenent are interplaced with the wiggler magnets. The quadrupoles have a $5 \mathrm{~cm}$ length and a maximum gralient of $100 \mathrm{G} / \mathrm{cm}$ and are separated by $0 . \pm \mathrm{m}$. the wiggler poriod. This focusing system provides a $j_{\max } \sim 1.3 \mathrm{~m}$ at the center of each quadrupole.

Before entering the wiggler. the electron bunch will be sufficiently focused to match the transport in the wiggler itself. Care is taken to aroid introducing dispersion and other chromatic effects that may lead to a buneh length increase. Leaving the wiggler. the clectron bunch is deterted be the dipole magnet wheh is then followed by a sutathe focusing elements for the beam disposal.

\section{THE RADIATION DETECTOR}

The most impertant part of the experiment is the measurement of the ranliation lost he the elertrons. The garliation hats a waselength in the fow

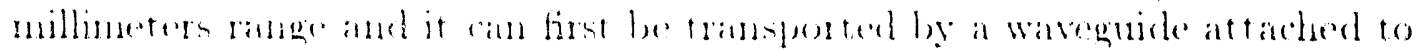
the and of the wigghet on one sick of the magnet which deflects the electrons

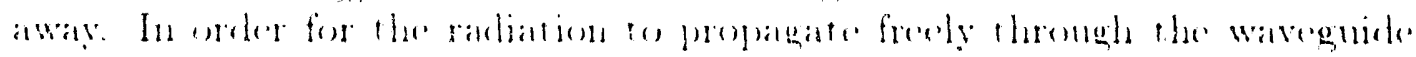

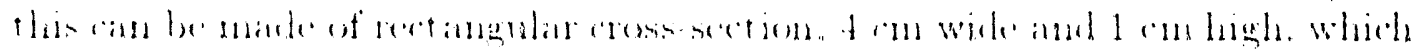


will serve also ats a filter to lower frequency noise radiation. The waveguide is $50 \mathrm{~cm}$ long and terminated at the receiving end with an adapter; if the adapter includes a resistive load, the square of the current flowing through the load is a direct measurement of the power being radiated. Other methods of measurement include directional couplers attached to the waveguide and followed by a frequency analyzer.

\section{COMPONENTS AND COST}

Table I gives a list of the components required for the execution of the experiment and the corresponding cost estimate. The total technical cost is $135 \mathrm{I} \$$ so which the labor of the equivalent two scientific man/year is to be added at $65 \mathrm{~K} \$$ each: finally a $35 \mathrm{~K} \$$ is added for travel, computing and other administrative tasks. The total cost of the experiment is thus $300 \mathrm{~K} \$$. To this one should add overhead, contingency and escalation. In order to procure the several parts, one might to have wait two years for the completion of the experiment in which case the spending profile can be split in $200 \mathrm{~K} \$$ for the first year and $100 \mathrm{~K} \$$ for the second. Once in place, the experiment itself should take only about 10 weeks run of the Accelerator Test Facility in order to gather all the necessary data.

\section{REFERENCES}

1. J. Schwinger. Phys. Rev. 70, No. 12 (1949), p. 1912.

2. J.M.J. Madey, J. Appl. Phys. 42, 1006 (1971).

3. J.D. Jackison. Classical Electrodynamics. Chapter 14, Second Edition, John Wiley \& Sons.

4. F.C. Michel. Phy. Rev. Letters, 48, No. 9, (1982), p. 580.

5. A.G. Ruggiero. AD/AP-35 and 41. BNL Intornal Reports (1992). See alse contribution on this subject in these conference proceeding's.

6. T. Nakazato et al. Phỵ. Rer. Letters. 63. No. 12 (1989). p. 1245.

7. E.B. Blum, ot al. N1.M A307. p. jos 11991$)$.

8. I. Ben-Zvi, 1991 Panticle Arederator Converence. IEEE 91CH30387. paige 550 .

9. P. Schoessow et al.. Promenlings of EPAC O0. Nice. France. June 1990, Vol. 1. p. 606.

\section{DISCLAIMER}

This report was prepared as an account of work sponsored by an agency of the United States Government. Neither the United States Government nor any agency thereof, nor any of their employees, makes any wareanty, express or implied, or assumes any legal liability or responsibility for the accuracy, completeness, or usefulness of any information, apparatus, product, or process disclosed, or represents that its use would not infringe privalely owned rights. Refer. ence herein to any specific commercial product, process, or service by trade name, trademark, manufacturer, or otherwise does not necessiarily constitute or imply its endorsemelt, recommendation, or favoring by the United States Government or any agency thereof. The viewy and opinions of authors expressed herein do not necessarily state or reflect those of the United States Government or any agency thereal. 
Table I Components and Cost

\begin{tabular}{|c|c|c|c|c|}
\hline Wiggler & 20 & $\begin{array}{l}\text { Dipoles } \\
\text { length } \\
B_{\text {max }} \\
\text { A perture }\end{array}$ & $\begin{array}{l}20 \mathrm{~cm} \\
1 \mathrm{kG} \\
8 \times 2 \mathrm{~cm}^{2}(H \times V)\end{array}$ & $50 \mathrm{~K} \$$ \\
\hline Focusing & $\begin{array}{l}3 \\
3\end{array}$ & $\begin{array}{l}\text { Quadrupoles } \\
\text { length } \\
G_{\max } \\
\text { Bore Radius } \\
\text { quadrupole triplet } \\
\text { between } R F \text { gun a } \\
\text { quads triplet after }\end{array}$ & $\begin{array}{l}\text { (QF or QD) } \\
5 \mathrm{~cm} \\
100 \mathrm{G} / \mathrm{cm} \\
4 \mathrm{~cm} \\
\text { et for natching } \\
\text { and wiggler } \\
\text { er deflecting dipole }\end{array}$ & 20 \\
\hline Deflecting Dipole & 1 & $\begin{array}{l}\text { length } \\
\text { field }\end{array}$ & $\begin{array}{l}0.2 \mathrm{~m} \\
1 \mathrm{kG} \text { (similar to wiggler) }\end{array}$ & 2.5 \\
\hline Vactum Chamber & & $\begin{array}{l}\text { stainless steel or a } \\
2 \text { mm thick } 8 \times 2 \\
\text { length }\end{array}$ & $\begin{array}{l}\text { aluminum } \\
2 \mathrm{~cm}^{2}(H \times V) \\
6 \mathrm{~m} \text { straight }\end{array}$ & 2 \\
\hline Waveguide & & $\begin{array}{l}0.5 \mathrm{~m} \text { long copper } \\
\text { attached with flar }\end{array}$ & $\begin{array}{l}4 \times 2 \mathrm{~cm}^{2} \\
\text { nges to v.c. }\end{array}$ & 0.5 \\
\hline Radiation Detectors & & & & 10 \\
\hline $\begin{array}{l}\text { Vacuum Valves } \\
\text { Punps }\end{array}$ & $\begin{array}{l}2 \\
2\end{array}$ & $\left(10^{-i}\right.$ torr $)$ & & 10 \\
\hline Power Supply for & $\begin{array}{l}\text { Dipoles } \\
\text { Quadrupoles }\end{array}$ & & & $\begin{array}{l}10 \\
10\end{array}$ \\
\hline $\begin{array}{l}\text { Dital Githering/Cont } \\
\text { 2-One mant ventr }\end{array}$ & mputer & & & $\frac{20}{135 \mathrm{KS}}$ \\
\hline Trivel computing. & ate. & & & $\frac{35}{300 \mathrm{Ks}}$ \\
\hline
\end{tabular}




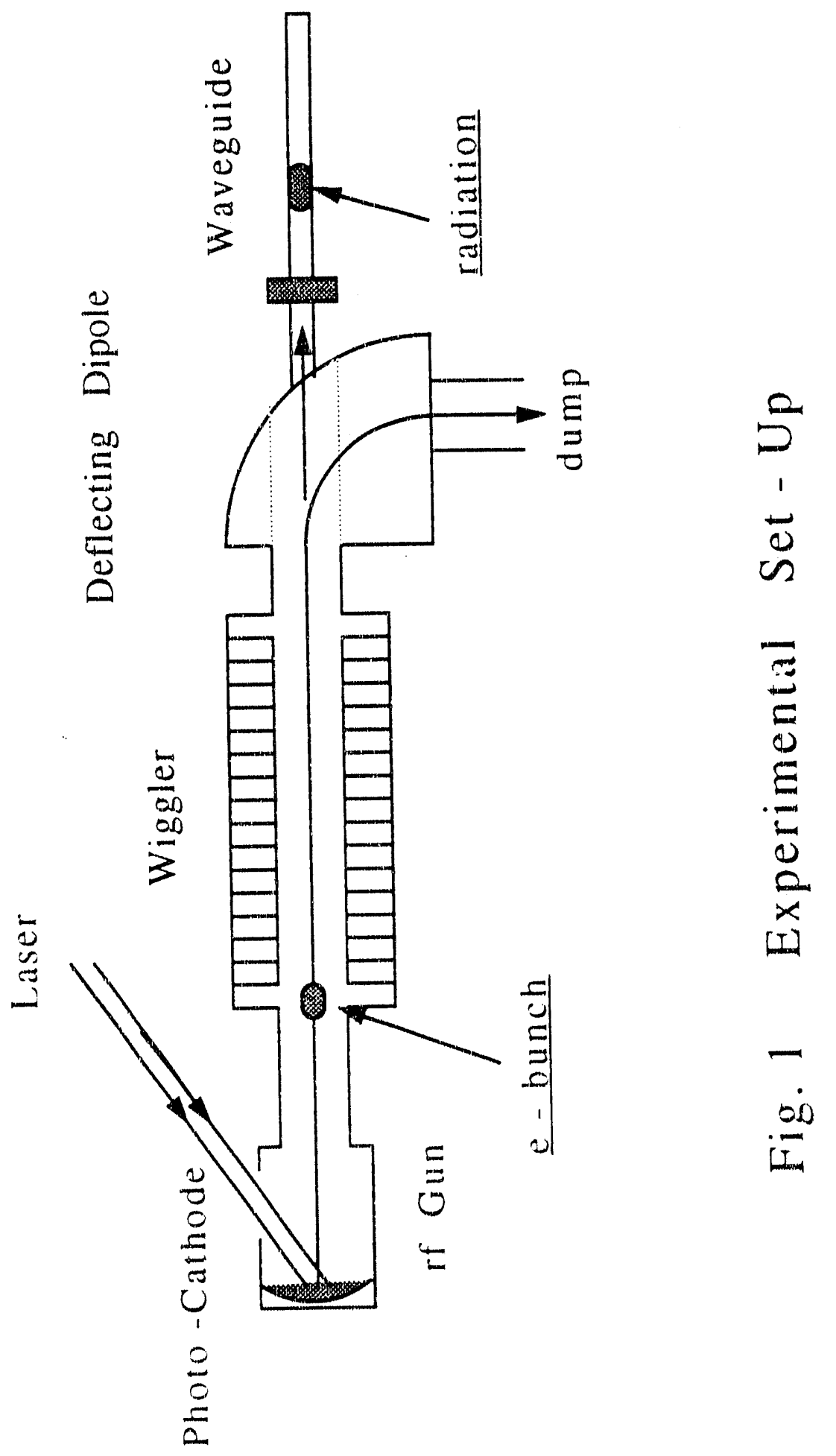



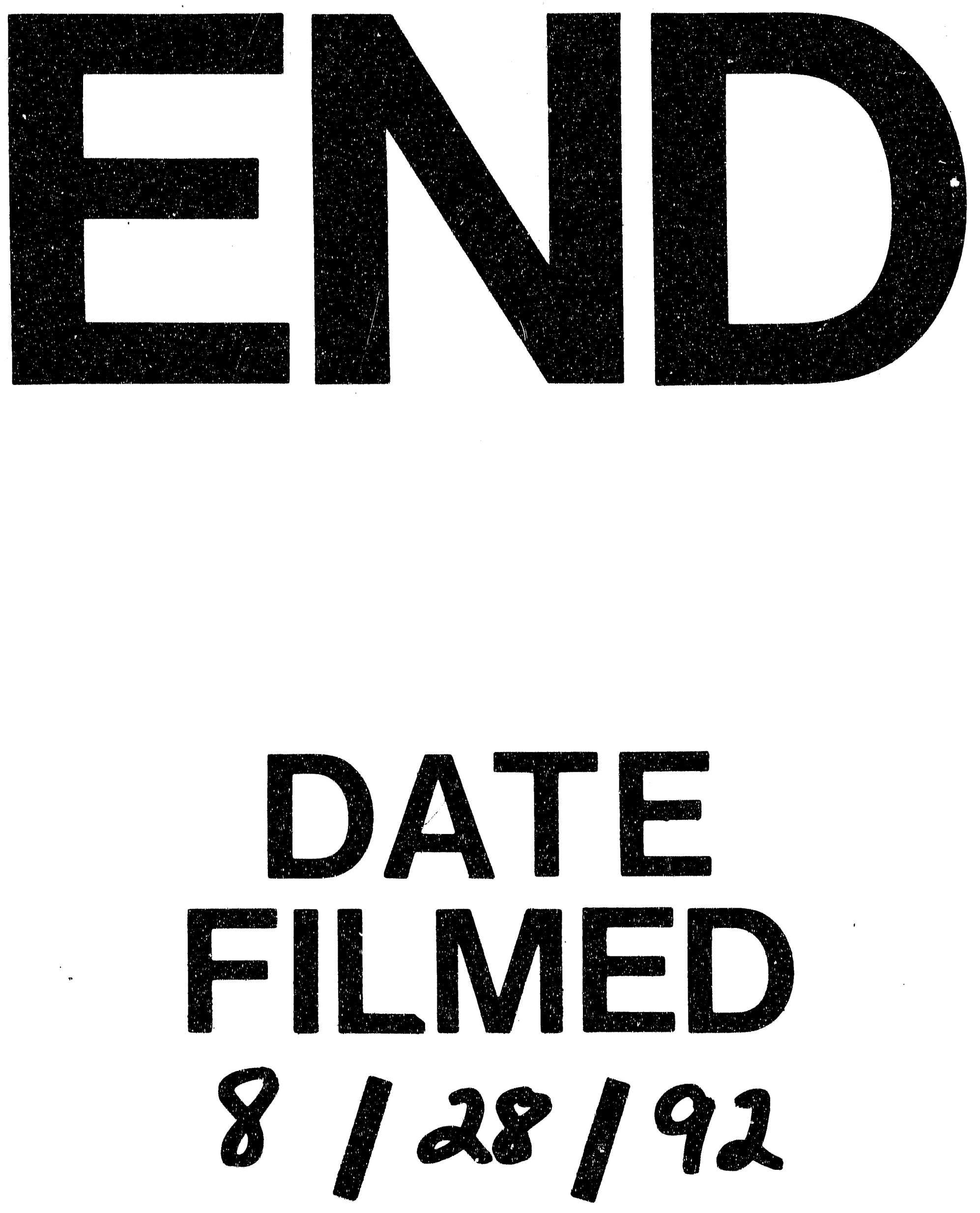
